\title{
Identification of differentially expressed genes according to chemosensitivity in advanced ovarian serous adenocarcinomas: expression of GRIA2 predicts better survival
}

\author{
CH Choi', J-J Choi', Y-A Park', Y-Y Lee', SY Song', CO Sung ${ }^{3}$, T Song', M-K Kim ${ }^{5}$, T-J Kim', J-W Lee', \\ H-J Kim', D-S Bae' and B-G Kim*,I
}

'Department of Obstetrics \& Gynecology, Samsung Medical Center, Sungkyunkwan University School of Medicine, 50 Inwon-dong, Gangnam-gu, Seoul 135-7I0, Korea; '2Department of Pathology, Samsung Medical Center, Sungkyunkwan University School of Medicine, Seoul 135-7I0, Korea; ${ }^{3}$ Department of Pathology, Asan Medical Center, University of Ulsan College of Medicine, Seoul, Korea; ${ }^{4}$ Department of Obstetrics and Gynecology, Gangnam CHA Medical Center, CHA University, Seoul, Korea; ${ }^{5}$ Department of Obstetrics \& Gynecology, Samsung Changwon Hospital, Sungkyunkwan University School of Medicine, Seoul $135-7$ I 0, Korea

\begin{abstract}
BACKGROUND: The purpose of this study was to identify genes that are differentially expressed in chemosensitive serous papillary ovarian carcinomas relative to those expressed in chemoresistant tumours.

METHODS: To identify novel candidate biomarkers, differences in gene expression were analysed in 26 stage IIIC/IV serous ovarian adenocarcinomas ( 12 chemosensitive tumours and 14 chemoresistant tumours). We subsequently investigated the immunohistochemical expression of GRIA2 in 48 independent sets of advanced ovarian serous carcinomas.

RESULTS: Microarray analysis revealed a total of 57 genes that were differentially expressed in chemoresistant and chemosensitive tumours. Of the 57 genes, 39 genes were upregulated and 18 genes were downregulated in chemosensitive tumours. Five differentially expressed genes (CD36, LIFR, CHLI, GRIA2, and FCGBP) were validated by quantitative real-time PCR. The expression of GRIA2 was validated at the protein level by immunohistochemistry, and patients with GRIA2 expression showed a longer progression-free and overall survival $(P=0.051$ and $P=0.031$ respectively).

CONCLUSIONS: We found 57 differentially expressed genes to distinguish between chemosensitive and chemoresistant tumours. We also demonstrated that the expression of GRIA2 among the differentially expressed genes provides better prognosis of patients with advanced serous papillary ovarian adenocarcinoma.

British Journal of Cancer (2012) 107, 91-99. doi:I0.1038/bjc.2012.217 www.bjcancer.com
\end{abstract}

Published online 29 May 2012

(C) 2012 Cancer Research UK

Keywords: gene expression profiling; microarray; ovarian serous adenocarcinoma; GRIA2; survival

Ovarian carcinoma remains the most lethal gynaecological tumour, ranking fifth in incidence of cancer deaths in women, and where $>70 \%$ of those affected are diagnosed with advanced disease (Runnebaum and Stickeler, 2001). Although many patients initially respond to combinations of cytoreductive surgery and platinum/taxane chemotherapy, most patients experience subsequent recurrences (International Collaborative Ovarian Neoplasm Group, 2002; du Bois et al, 2003).

It is difficult to predict the clinical outcome of patients with advanced ovarian cancer, and as such, the prognostic factors available today need to be improved. In ovarian cancer, gene expression profiles have so far been used to identify gene expression signatures that correlate with clinical outcome, to determine which genes affect survival and relapse, and to generate biomarkers that could predict patient response to chemotherapy (Collins et al, 2004; Lancaster et al, 2004; Spentzos et al, 2004; Berchuck et al, 2005; Hartmann et al, 2005). However, none of the genes have been

*Correspondence: Professor B-Gie Kim; E-mail: huna0@naver.com. Received I November 2011; revised 12 April 2012; accepted 17 April 2012; published online 29 May 2012 validated adequately or proven to provide superior predictive value in prospective studies (Dupuy and Simon, 2007). Interestingly, there is typically very little overlap between the gene lists reported by various groups. These discrepancies might be related to the use of different microarray platforms with different normalisation methods and differences in the degree of contamination by non-neoplastic cells in specimens, or heterogeneity in the patient population undergoing study (Konstantinopoulos et al, 2008).

Although several gene expression profiling studies were performed in homogenous groups of patients (Berchuck et al, 2005; Bachvarov et al, 2006; Ouellet et al, 2006; Trinh et al, 2011), many other studies compared tumour groups with different histological subtypes and stages. As some differences in expression could depend on histological tumour type and stage, it is important to study homogeneous tumour groups in survival analyses. Recently, there are publications using microdissected ovarian cancer tissue and a homogenous tumour group to identify prognostic markers for ovarian cancer (Mok et al, 2009; Cancer Genome Atlas Research Network, 2011).

In this study, we investigated gene expression differences in a homogeneous group of patients with stage IIIC/IV serous ovarian adenocarcinomas. The gene expression of the 12 tumours from 
chemosensitive patients were compared with 14 tumours from chemoresistant patients. This comparison showed that 57 genes were differentially expressed and the genes were compared in the TCGA dataset. We subsequently investigated the immunohistochemical expression of GRIA2 as a candidate prognostic marker in 48 independent sets of advanced ovarian serous papillary adenocarcinoma specimens.

\section{METHODS}

\section{Ovarian cancer samples}

Twenty-six snap-frozen stage IIIC/IV serous papillary adenocarcinomas of the ovary were collected prospectively from patients diagnosed between 2003 and 2007 at the Samsung Medical Center with IRB approval. Each tumour specimen was $\sim 1 \mathrm{~cm}^{3}$ in size and were maintained a temperature of less than $-80^{\circ} \mathrm{C}$. Each sample was analysed histologically by a staff pathologist, and only tumour samples containing at least $70 \%$ tumour epithelial cells were included. The clinicopathological features are summarised in Table 1. All of the patients were treated with maximal debulking surgery, which was followed by a combination of paclitaxel/ carboplatin. Cases were staged according to the 1988 FIGO staging system. Debulking status was defined according to the size of the nodules left after surgery $(<1 \mathrm{~cm}$, optimal; $\geqslant 1 \mathrm{~cm}$, suboptimal). Fourteen patients had recurrences within 6 months following treatment and were considered chemoresistant. The remaining 12 patients had no recurrences or recurrences beyond 24 months. The median follow-up time was 41 months (range, 11-86 months). For the present study, FIGO stages I-IIIB tumours or patients with follow-up time $<24$ months were excluded.

For validation of PCR, another 40 snap-frozen stage III-IV serous adenocarcinomas were selected. Patients were divided into two groups according to the sensitivity for taxane/platinum combination chemotherapy: platinum resistant was defined as platinum-free interval $<6$ months; platinum-sensitive, and platinum-free interval $\geqslant 6$ months. The clinical features are summarised in Supplementary Table 1.

Forty-eight paraffin-embedded serous ovarian adenocarcinoma specimens were selected for immunohistochemical staining, and grade 1 or stage I tumours were excluded in the cohort.

\section{RNA isolation and gene expression profiling}

In the present study, we performed global gene expression analyses using AffymetrixGeneChip Human Gene 1.0 ST oligonucleotide

Table I Clinical and pathological characteristics of the patients with serous ovarian carcinoma

\begin{tabular}{lccc}
\hline & Chemoresistant & Chemosensitive & P-value \\
\hline No. & 14 & 12 & \\
$\begin{array}{l}\text { Age, years } \\
\text { Median (range) }\end{array}$ & $50(33-68)$ & $49(40-75)$ & 0.70 \\
$\begin{array}{l}\text { Histological grade } \\
\text { I,2 }\end{array}$ & $4(28.6 \%)$ & $2(16.7 \%)$ & 0.26 \\
3 & $10(71.4 \%)$ & $10(83.3 \%)$ & \\
Stage & & & \\
IIIC & $12(85.7 \%)$ & $8(66.7 \%)$ & 0.24 \\
IV & $2(14.3 \%)$ & $4(33.3 \%)$ & \\
Optimal debulking & $5(35.7 \%)$ & $7(58.3 \%)$ & 0.43 \\
Percentage of tumour cells & & & \\
Median (range) & $83 \%(70-90)$ & $85 \%(70-95)$ & 0.52 \\
\hline
\end{tabular}

arrays (Affymetrix, http://www.affymetrix.com). The sample preparation was performed according to the instructions and recommendations provided by the manufacturer. Total RNA was isolated using RNeasy Mini Kit columns as described by the manufacturer (Qiagen, Hilden, Germany). The quality of RNA was assessed by an Agilent 2100 bioanalyser using the RNA 6000 Nano Chip (Agilent Technologies, Amstelveen, The Netherlands), and the quantity was determined by a ND-1000 spectrophotometer (NanoDrop Technologies, Inc., Wilmington, DE, USA) (Supplementary Figure 1). For each RNA sample, $300 \mathrm{ng}$ was used as input into the Affymetrix procedure, as recommended by protocol. Briefly, $300 \mathrm{ng}$ of total RNA from each sample was converted to double-strand cDNA. Using a random hexamer incorporating a T7 promoter, amplified RNA (cRNA) was generated from the double-stranded cDNA template though an in vitro transcription reaction and purified with the Affymetrix sample cleanup module. cDNA was regenerated through a random-primed reverse transcription using a dNTP mix containing dUTP. The cDNA was then fragmented by UDG and APE 1 restriction endonucleases and end-labelled by a terminal transferase reaction incorporating a biotinylated dideoxynucleotide. Fragmented end-labelled cDNA was hybridised to the GeneChip Human Gene 1.0 ST arrays for $16 \mathrm{~h}$ at $45^{\circ} \mathrm{C}$ and 60 r.p.m., as described in the Gene Chip Whole Transcript Sense Target Labelling Assay Manual (Affymetrix). With $\sim 4$ probes per exon and roughly 26 probes per gene, the GeneChip Human Gene 1.0 ST arrays enables two complementary levels of analysis-gene expression and alternative splicing. After hybridisation, the chips were stained and washed in a Genechip Fluidics Station 450 and scanned using a Genechip Array scanner 3000 7G. The assays were performed blinded to the study end point.

The expression intensity data were extracted from the scanned images using Affymetrix Command Console Software (version 1.1) and stored as .cel files. To remove bias between the samples, the intensity values were normalised using the robust multi-average (RMA) algorithm implemented in the Affymetrix Expression Console Software (version 1.1). To determine whether or not the genes were differentially expressed between the two groups, we performed an unpaired Student's $t$-test on the RMA expression values, and genes with $P$-values $<0.05$ were extracted (Irizarry et al, 2003). Highly expressed genes that showed greater than a two-fold difference between the average signal values of the control and test groups were selected for further study. To classify the coexpression gene groups which have similar expression patterns, hierarchical clustering analysis was performed with the Multi Experiment Viewer software (version 4.4; http://www.tm4.org) (Saeed et al, 2003, 2006). The web-based tool Database for Annotation, Visualisation, and Integrated Discovery was used to perform the biological interpretation of the differentially expressed genes (Huang da et al, 2009a, b). The genes were classified based on the information of gene function in Gene ontology and KEGG pathway databases (http://david.abcc.ncifcrf.gov/home.jsp).

\section{Validation of gene expression by quantitative real-time PCR}

To validate the results of the oligonucleotide microarray analysis, five genes (CD36, LIFR, CHL1, GRIA2, and FCGBP) that were shown to be differentially expressed were analysed with a real-time (RT)-PCR. The cDNA synthesis was performed with a High Capacity cDNA Archive kit (4368813; Applied Biosystems, Foster City, CA, USA) following the protocol supplied. TaqMan PCR was done with an ABI PRISM 7900HT Fast-Time PCR System (Applied Biosystems) according to the manufacturer's instructions. Real-time PCR primers and probes for CD36 (Hs01567186), LIFR (Hs01123581), CHL1 (Hs00544091), GRIA2 (forward 5'-GTTTTCC TTGGGTGCCTTTATGC- ${ }^{\prime}$, reverse 5'-CCAACAATGCGCCCAGAGA-3', probe $5^{\prime}$-TTCGCCAAGATCCC-3'), FCGBP (Hs01553051), and 
GAPDH (4310884E) were purchased from Applied Biosystems (Supplementary Figure 2). The relative expressions of these mRNAs were normalised to the amount of GAPDH in the same cDNA by using the $\Delta \Delta C_{\mathrm{t}}$ method described by the manufacturer (Lee et al, 2008).

\section{Immunohistochemistry on formalin-fixed tissues}

We also performed immunohistochemical staining for GRIA2 to determine whether or not there was a correlation between the gene expression and clinical outcomes. GRIA2 was found to be upregulated in chemosensitive tumours. Interestingly, there have been conflicting reports on the role of GRIA2 with regard to cancer biology. It has been reported not only to be upregulated in the neuroendocrine carcinoma cells (Tsibris et al, 2003; Leja et al, 2009), but also has been reported to be associated with a low degree of malignancy compared with high-grade glioblastoma multiforme (GBM; Beretta et al, 2009). In addition, there has been no report on GRIA2 in ovarian cancer. Thus, we selected the GRIA2 expression as a candidate prognostic marker in this study.

Immunohistochemical staining was performed with the standard peroxidase/DAB method (DakoCytomation, Inc., Carpinteria, CA, USA) on formalin-fixed, paraffin-embedded $4-\mu \mathrm{m}$ thick tissue sections. To increase specificity and sensitivity, samples were pretreated with target retrieval solution ( $\mathrm{pH} 9$, S2367; DakoCytomation) at $97^{\circ} \mathrm{C}$ for $20 \mathrm{~min}$. GRIA2 expression was detected using primary rabbit polyclonal, mono-specific antibody (ANTI-GRIA2, HPA008441; Atlas Antibodies, Stockholm, Sweden) at a $1: 20$ dilution for $24 \mathrm{~h}$ at room temperature in a humidified chamber. Immunohistochemical procedures were performed as described previously (Kim et al, 2010). Antigen antibody complexes were detected with the Dako REAL DAB/Chromogen (K5007; DakoCytomation) according to the manufacturer's instructions. Tissue sections were lightly counterstained with haematoxylin, and then examined by light microscopy. To verify antibody specificity, antimouse IgG (AI-2000; Vector Laboratories, Burlingame, CA, USA) was used in place of the primary antibody as a negative control, and brain (cerebellum) was used as positive control.

Immunoreactivity of GRIA2 in cancer cells was evaluated according to intensity and area (Michalski et al, 2008). The intensity of cancer cells was recorded as 'no staining (0)', 'weak to moderate staining (1)' or 'strong staining (2)'. The area of stained cancer cells was recorded as $<33 \%$ (1), 33-66\% (2) or $>66 \%$ (3) of all cancer cells. These numbers were then multiplied resulting in a score of 0-6. We arbitrarily classified a score $>2$ as GRIA2 positive. The cutoff points were based on the distribution of the staining results and statistical significance. We judged the expression as either positive or negative according to the membranous staining.

\section{Data analysis}

After confirming whether the data were normally distributed using the Shapiro-Wilk test, we used the Wilcoxon rank sum test to compare the PCR data. Fisher's exact probability test or the chisquare test was used to test possible associations between the expression of GRIA2 and various clinicopathological factors. Overall survival was defined as the interval from the date of initial surgical resection to the date of last known contact or death. Progression-free survival was defined as the interval from the date of initial surgical resection to the date of progression, date of recurrence, or date of last known contact if the patient was alive and has not recurred. Kaplan-Meier curves were plotted to assess the effects of GRIA2 expression on survival. These survival curves were compared using the log-rank test. The Cox proportional hazard models were used to assess multiple factors. $P$-values $<0.05$ were considered statistically significant. All statistical analyses were performed using SPSS (version 15.0; SPSS, Inc., Chicago, IL, USA).

\section{RESULTS}

Gene expression analysis and clustering of chemosensitive and chemoresistant tumours

Comprehensive gene expression profiles of 14 chemoresistant and 12 chemosensitive samples were generated with high-density oligonucleotide arrays. After the most 'absent' genes were filtered out, a significance analysis of the microarrays test revealed a total of 57 genes that had a $P$-value $<0.05$ and at least a two-fold change. Of the 57 genes, 39 genes were found to be upregulated (Table 2), and 18 genes were downregulated (Table 3) in chemosensitive tumours. To further visualise differences in gene expression between the chemosensitive and chemoresistant tumours, a hierarchical clustering of the 57 genes was performed (Figure 1).

\section{Validation of gene expression by quantitative RT-PCR}

Five differentially expressed genes (CD36, LIFR, CHL1, GRIA2, and $F C G B P$ ) were selected for verification of the microarray data with quantitative (Q)PCR analysis. The quantitative RT-PCR data were correlated with the microarray data, confirming the reliability of our expression data (Figure 2, Supplementary Figures 3 and 4). In four of five genes, we found a statistically significant difference in the gene expressions between the chemosensitive and the chemoresistant tissues (Figure 2A, Supplementary Figure 1). The differences were also validated in an additional 40 patients cohort (Figure 2B).

\section{Expression of GRIA2 correlates with survival}

As shown in Figure 3, a strong expression for GRIA2 protein was found on the membranes of the malignant cells. GRIA2 expression was detected in 6 of 48 samples (12.5\%), and was not correlated with age, stage, and residual tumour after surgery (Table 4). And interestingly, GRIA2 expression was correlated with a longer progression-free and overall survival (Figure 4). On the basis of multivariate analysis, GRIA2 expression remains a significant predictor of better progression-free survival $(P=0.026$; Table 5$)$.

\section{Downregulation of GRIA2 increases cell survival of ovarian cancer cells in vitro}

Next, we evaluated the effect of GRIA2 on the survival of epithelial ovarian cancer cells (Figure 5). We tried to examine whether regulation of expression level of GRIA2 could change cell survivability in vitro using siRNA. First, we estimated the protein expression level of GRIA2 in the epithelial ovarian cancer cell lines and selected SKOV3 and HeyA8 cells for in vitro test. After checking the effect of GRIA2 siRNA, we estimated GRIA2 siRNA induced modification of cell survival of two cells by MTT assay. Interestingly, GRIA2 siRNA increased 0.1 - and 0.13 -fold relative cell survival of SKOV3 and HeyA8 cells, respectively (Figure 5D and $\mathrm{E})$. These results might imply the negative association of GRIA2 expression and cell survivability of epithelial ovarian cancer cells.

\section{DISCUSSION}

In this study we used oligonucleotide microarrays to identify differences in expression levels in 26 stage IIIC/IV ovarian serous adenocarcinomas (12 chemosensitive tumours vs 14 chemoresistant tumours). We detected 57 differentially expressed genes, 5 of which were validated with QPCR analysis. In the present study we focused on GRIA2 because this gene had low $P$-values and displayed a large fold change. We showed that GRIA2 was downregulated in chemoresistant tumours, which strengthen 
Table 2 Upregulated genes expressed at least two-fold higher in chemosensitive tumours compared with chemoresistant tumours

\begin{tabular}{|c|c|c|c|c|}
\hline Gene symbol & Gene name & $P$-value & FDR & Log2 ratio \\
\hline NTS & Neurotensin & 0.0107 & 0.2488 & 1.83 \\
\hline $\mathrm{CHLI}$ & Cell adhesion molecule with homology to LICAM (close homologue of LI) & 0.0053 & 0.0312 & 1.47 \\
\hline GRIA2 & Glutamate receptor, ionotropic, AMPA 2 & 0.0460 & 0.0200 & 1.41 \\
\hline MPPED2 & Metallophosphoesterase domain containing 2 & 0.0037 & 0.0279 & 1.39 \\
\hline LIFR & Leukaemia inhibitory factor receptor alpha & 0.0002 & 0.0033 & 1.28 \\
\hline AREG & Amphiregulin & 0.0248 & 0.0309 & 1.24 \\
\hline CT45A6 & Cancer/testis antigen family 45, member A6 & 0.0447 & 0.2977 & 1.21 \\
\hline RERG & RAS-like, oestrogen-regulated, growth inhibitor & 0.0145 & 0.0899 & 1.19 \\
\hline CRISP3 & Cysteine-rich secretory protein 3 & 0.0444 & 0.2970 & 1.19 \\
\hline CCLI8 & Chemokine ( $\mathrm{C}-\mathrm{C}$ motif) ligand I 8 (pulmonary and activation-regulated) & 0.0429 & 0.2942 & 1.17 \\
\hline IGF2BP3 & Insulin-like growth factor 2 mRNA binding protein 3 & 0.0195 & 0.2551 & 1.17 \\
\hline CT45A2 & Cancer/testis antigen family 45, member $\mathrm{A} 2$ & 0.0423 & 0.2935 & 1.12 \\
\hline- & 8084878 & 0.0161 & 0.0006 & 1.12 \\
\hline ARMC3 & Armadillo repeat containing 3 & 0.0292 & 0.0142 & 1.12 \\
\hline SNORA4 & Small nucleolar RNA, H/ACA box 4 & 0.0119 & 0.0002 & 1.11 \\
\hline CT45A5 & Cancer/testis antigen family 45, member A5 & 0.0411 & 0.2919 & 1.08 \\
\hline CDC2 & Cell division cycle $2, \mathrm{G} 1$ to $\mathrm{S}$ and $\mathrm{G} 2$ to $\mathrm{M}$ & 0.0130 & 0.0032 & 1.07 \\
\hline HSDL2 & Hydroxysteroid dehydrogenase like 2 & 0.0052 & 0.0062 & 1.06 \\
\hline MLLT3 & Myeloid/lymphoid or mixed-lineage leukaemia (trithorax homologue, Drosophila); translocated to, 3 & 0.0008 & 0.0084 & 1.05 \\
\hline NRG4 & Neuregulin 4 & 0.0331 & 0.0845 & 1.05 \\
\hline SLC4OAI & Solute carrier family 40 (iron-regulated transporter), member I & 0.0228 & 0.0977 & 1.04 \\
\hline- & 8124846 & 0.0153 & 0.0006 & 1.03 \\
\hline AP3M2 & Adaptor-related protein complex 3 , mu 2 subunit & 0.0013 & 0.0001 & 1.03 \\
\hline C5orf54 & Chromosome 5 open reading frame 54 & 0.0082 & 0.0020 & 1.02 \\
\hline GPM6B & Glycoprotein M6B & 0.0213 & 0.0247 & 1.02 \\
\hline
\end{tabular}

Table 3 Downregulated genes expressed at least two-fold higher in chemosensitive tumours compared with chemoresistant tumours

\begin{tabular}{|c|c|c|c|c|}
\hline Gene symbol & Gene name & $P$-value & FDR & Log2 ratio \\
\hline ITGB4 & Integrin, beta 4 & 0.0375 & 0.0104 & -1.01 \\
\hline$P D Z K|| P \mid$ & PDZKI interacting protein I & 0.0273 & 0.2615 & -1.03 \\
\hline CLDNI & Claudin I & 0.0143 & 0.2494 & -1.03 \\
\hline LRRN4 & Leucine rich repeat neuronal 4 & 0.0183 & 0.2549 & -1.05 \\
\hline LICAM & LI cell adhesion molecule & 0.0366 & 0.0379 & -1.09 \\
\hline ITGA3 & Integrin, alpha 3 (antigen CD49C, alpha 3 subunit of VLA-3 receptor) & 0.0041 & 0.0314 & -1.11 \\
\hline GPX3 & Glutathione peroxidase 3 (plasma) & 0.0387 & 0.0348 & -1.11 \\
\hline $\mathrm{C} 3$ & Complement component 3 & 0.0043 & 0.0144 & -1.18 \\
\hline WNT7A & Wingless-type MMTV integration site family, member 7A & 0.0389 & 0.0210 & -1.21 \\
\hline Clorfl 86 & Chromosome I open reading frame 186 & 0.0359 & 0.2808 & -1.26 \\
\hline LOC613266 & Hypothetical LOC6I3266 & 0.0247 & 0.0706 & -1.29 \\
\hline
\end{tabular}

GRIA2 as a target for further evaluation as a prognostic marker for ovarian cancer. This study has some limitations. First, the tumour tissue was not microdissected, and therefore it may comprise up to $30 \%$ non-tumour tissue. Second, our data were based on a small sample size. Nonetheless, to our knowledge, this is the first report demonstrating the correlation between GRIA2 expression and prognosis in patients with ovarian cancer.

The 56 genes found in this study were tested in a set consisting of 489 samples available through TCGA. Using univariate Cox model, expression of the four genes (CCL18, GPM6B, MMP9, and 


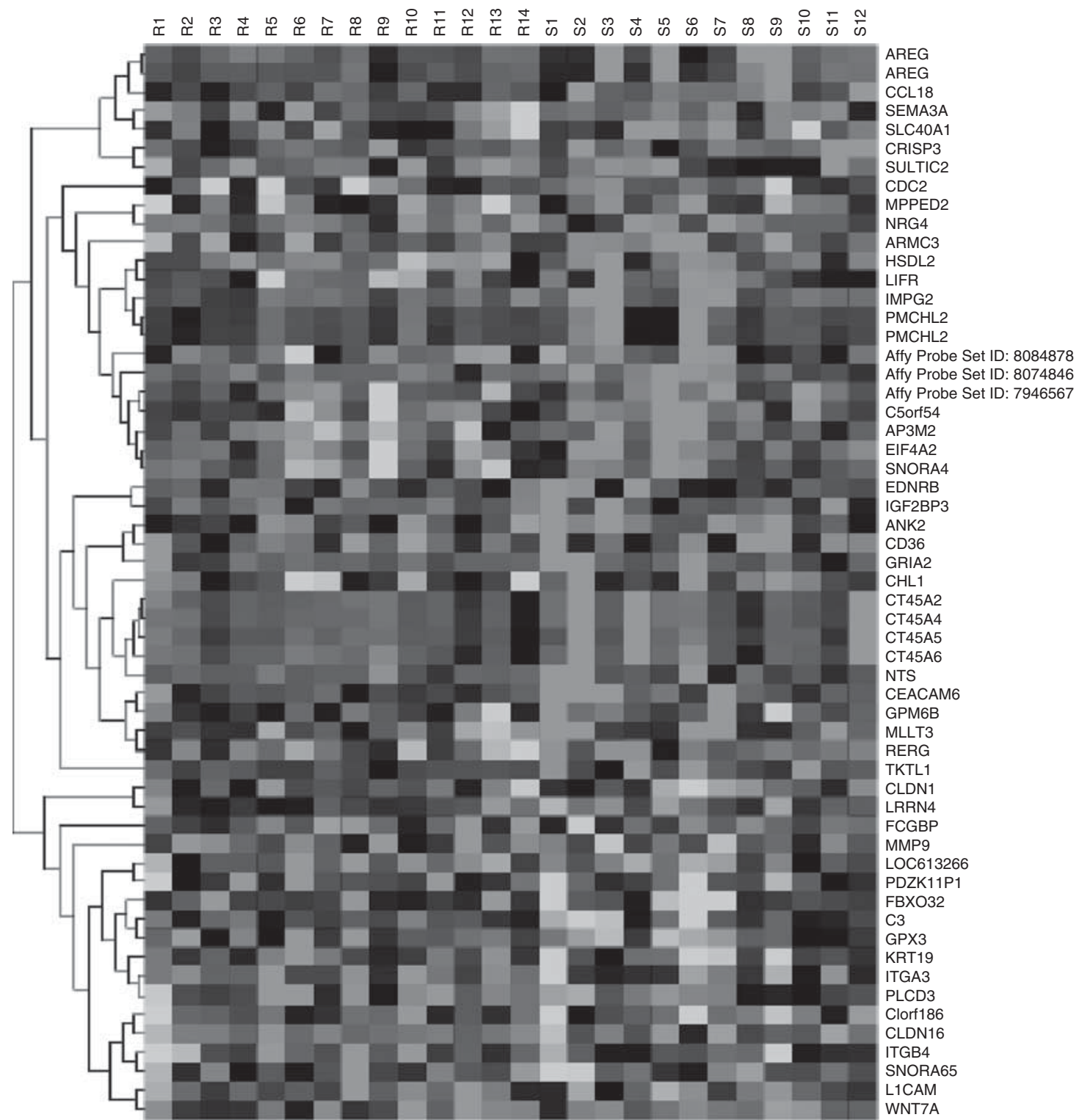

Figure I Unsupervised hierarchical clustering analysis of 26 serous papillary ovarian carcinomas ( 14 chemoresistant tumours and 12 chemosensitive tumours). We identified 39 upregulated (more than two-fold change) and 18 downregulated (more than two-fold change; $P<0.05$ ) genes in chemosensitive tumours. Abbreviations: $\mathrm{R}$, chemoresistant tumours; $\mathrm{S}$, chemosensitive tumours.

$F C G B P$ ) was associated with overall survival in the validation set (Supplementary Table 2). Kaplan-Meier survival curve showed that six of the nine genes selected (CHL1, GRIA2, CD36, LIFR, FCGBP, CCL18, GPM6B, and MMP9) were correlated with overall survival (Supplementary Figures 5 and 6).

GRIA2 encodes an alpha-amino-3-hydroxy-5-methyl-4-isoxazolepropionic acid (AMPA) glutamate receptor, which acts as an excitatory neurotransmitter at many synapses in the central nervous system. AMPA receptors are composed of four types of subunits (GluR1, GluR2, GluR3, and GluR4), which combine to form tetramers (Hansen et al, 2007).

The presence of the GluR2 subunit determines AMPA receptor impermeability to $\mathrm{Ca}^{2+}$ (Seeburg, 1993; Hollmann and Heinemann, 1994; Rao and Finkbeiner, 2007). As AMPA receptor activation regulates the differentiation, proliferation, and migration of embryonic stem cells (Behar et al, 1999; Ikonomidou et al, 1999; Joo et al, 2007), it has been hypothesised that modulation of AMPA receptor-mediated signals might be involved in carcinogenesis. This hypothesis has subsequently been proven for some tumour entities, such as astrocytomas, glioblastomas, breast carcinomas, lung carcinomas, colon adenocarcinomas, and prostate carcinomas (Yoshioka et al, 1996; Takeda et al, 2000; Rzeski et al, 2001; Abdul and Hoosein, 2005; Ishiuchi et al, 2007). Alexander et al have shown that glutamate-mediated AMPA receptor activation increases invasion and migration of pancreatic cancer cells via activation of the classical MAPK pathway (Herner et al, 2011).

In contrast, there are reports that have shown endogenous GluR2 expression is associated with a low degree of malignancy. Beretta et al (2009) have shown that endogenous GluR2 is expressed in slow-growing GBM-derived tumour stem cells (GBM TSCs) and low-grade tumour specimens, but not in fast-growing gliomas or high-grade tumour specimens. More remarkably, GluR2 overexpression in U-87MG cells inhibits proliferation by inactivating extracellular signal-regulated kinase1/2-Src phosphorylation and induces apoptosis. Moreover, RNAi experiments in a low-grade cell line have shown that downregulation of GluR2 causes a significant acceleration of cell proliferation. With regard to the study 

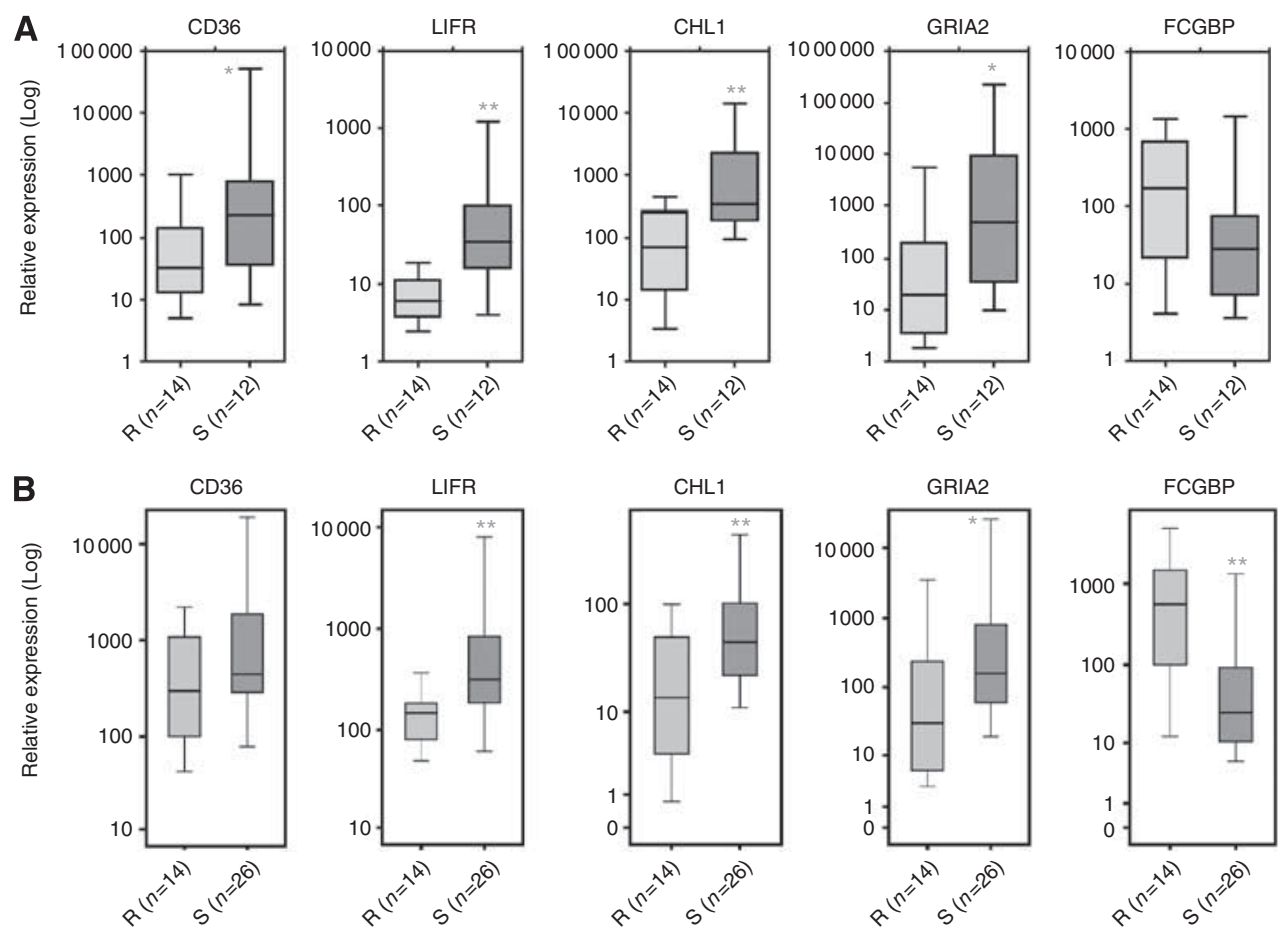

Figure 2 Real-time quantitative PCR analysis of the five selected genes (CD36, LIFR, CHLI, GRIA2, and FCGBP) differentially expressed between chemosensitive (pink colour) and chemoresistant (blue colour) tumours in the same cohort (A) and in another 40 patients cohort (B). Statistically significant difference between the chemosensitive and the chemoresistant tissues were found in four of five genes for each cohort. Abbreviations: R, chemoresistant tumours; $\mathrm{S}$, chemosensitive tumours. ${ }^{*} P<0.05,{ }^{*} * P<0.01$. The colour reproduction of this figure is available at the Britsh Journal of Cancer online.
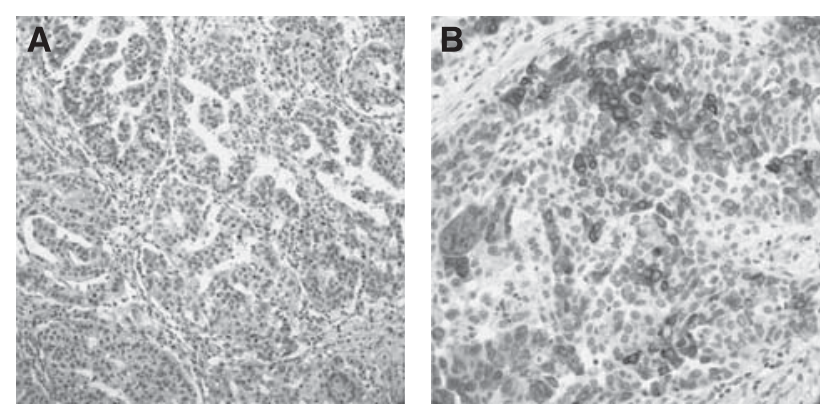

Figure 3 Representative immunohistochemical staining for GRIA2 protein. (A) Negative expression (original magnification $\times 200$ ). (B) Strong expression for GRIA2 protein on the membranes of the malignant cells (original magnification $\times 400$ ).

of biomarkers in cancers, Trinh et al (2011) have suggested an interesting opposite confounding of prognostic $v s$ predictive factors. The study analysed the oncogenic pathway profiling in advanced serous ovarian carcinomas. Unexpectedly, it was revealed that invasive gene signature and wound healing response were increased in chemosensitive tumours and not in the chemoresistant ones. GRIA2 might be one of the examples of such a confounding factor.

In this study, downregulation of GRIA2 was found in cases with a poorer prognosis. Among the many mechanisms, epigenetic silencing can cause downregulation of genes. Interestingly, Carmen et al have examined an Epigenetic-Aging-Signature, and GRIA2 hypermethylation was found to be associated with aging (Koch and Wagner, 2011). Although we could not find studies about the downregulation of GRIA2 in drug-resistant tumours, GRIA2 have been reported to be repressed by oestrogen. Greathouse et al (2008) have identified GRIA2 as oestrogen-responsive genes in uterine leiomyoma.
Table 4 Distribution of GRIA2 expression according to clinicopathological characteristics of the serous papillary ovarian carcinoma $(n=48)$

\begin{tabular}{|c|c|c|c|c|}
\hline \multirow[b]{2}{*}{ Characteristics } & \multirow[b]{2}{*}{ No. (\%) } & \multicolumn{3}{|c|}{ GRIA2 expression } \\
\hline & & Positive & Negative & $P$-value \\
\hline Total & & $6(12.5 \%)$ & $42(87.5 \%)$ & \\
\hline \multicolumn{5}{|l|}{ Age, years } \\
\hline Median (range) & & $56(50-75)$ & $53(3 \mid-78)$ & 0.407 \\
\hline \multicolumn{5}{|l|}{ CA- 25 level $\left(\mathrm{Uml}^{-1}\right)$} \\
\hline Mean \pm s.d. & & $3545 \pm 4053$ & $|889 \pm 320|$ & 0.257 \\
\hline \multicolumn{5}{|l|}{ Histological grade } \\
\hline 2 & $10(20.8)$ & 3 & 7 & 0.095 \\
\hline 3 & $38(79.2)$ & 3 & 35 & \\
\hline \multicolumn{5}{|l|}{ Stage } \\
\hline$\|$ & $6(12.5)$ & 2 & 4 & 0.157 \\
\hline III/IV & $42(87.5)$ & 4 & 38 & \\
\hline \multicolumn{5}{|l|}{ Optimal debulking } \\
\hline Optimal & $22(45.8)$ & । & 21 & 0.199 \\
\hline Suboptimal & $26(54.2)$ & 5 & 21 & \\
\hline \multicolumn{5}{|l|}{ Response to chemotherapy } \\
\hline Sensitive & $40(83.3)$ & 6 & 34 & $0.57 \mid$ \\
\hline Resistant & $8(16.7)$ & 0 & 8 & \\
\hline \multicolumn{5}{|l|}{ Survival status } \\
\hline Died of disease & $19(39.6)$ & 0 & 19 & 0.149 \\
\hline Died of another pathology & I (2.1) & 0 & । & \\
\hline Alive with disease & $12(25.0)$ & 2 & 10 & \\
\hline Alive without disease & $16(33.3)$ & 4 & 12 & \\
\hline
\end{tabular}


Of the five genes identified, three genes (GRIA2, CHL1, and FGBP) showed same prognostic significance in our data and the TCGA data. FCGBP is Fc fragment of IgG-binding protein and there are no studies in ovarian cancer. CHL1 is an adhesion
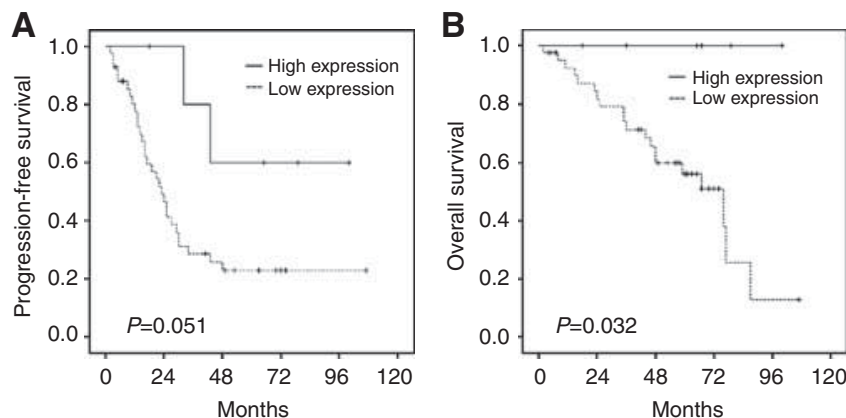

Figure 4 Correlations between GRIA2 protein expression and progression-free $(\mathbf{A})$ and overall $(\mathbf{B})$ survival. The survival was longer in six patients with GRIA2-positive tumours than in 42 patients with GRIA2negative tumours.

Table 5 Univariate and multivariate analysis for progression-free survival $(n=48)$

\begin{tabular}{|c|c|c|c|c|c|c|}
\hline \multirow[b]{2}{*}{ Variables } & \multicolumn{3}{|c|}{ Univariate } & \multicolumn{3}{|c|}{ Multivariate } \\
\hline & HR & $95 \% \mathrm{Cl}$ & $\begin{array}{c}P- \\
\text { value }\end{array}$ & HR & $95 \% \mathrm{Cl}$ & $\begin{array}{c}P \text { - } \\
\text { value }\end{array}$ \\
\hline Age (years): $>50$ vs $\leqslant 50$ & 1.45 & $0.71-2.94$ & 0.306 & 1.69 & $0.82-3.50$ & 0.159 \\
\hline CAI 25: > 674 vs $\leqslant 674$ & 1.58 & $0.78-3.18$ & 0.205 & 1.47 & $0.73-2.98$ & 0.284 \\
\hline $\begin{array}{l}\text { Surgery: optimal vs } \\
\text { suboptimal }\end{array}$ & 0.77 & $0.38-1.55$ & 0.461 & 0.70 & $0.34-1.43$ & 0.326 \\
\hline GRIA2 expression & 0.27 & $0.06-1.12$ & 0.072 & 0.19 & $0.04-0.82$ & 0.026 \\
\hline
\end{tabular}

Abbreviations: $\mathrm{Cl}=$ confidence interval; $\mathrm{HR}=$ hazard ratio.

A
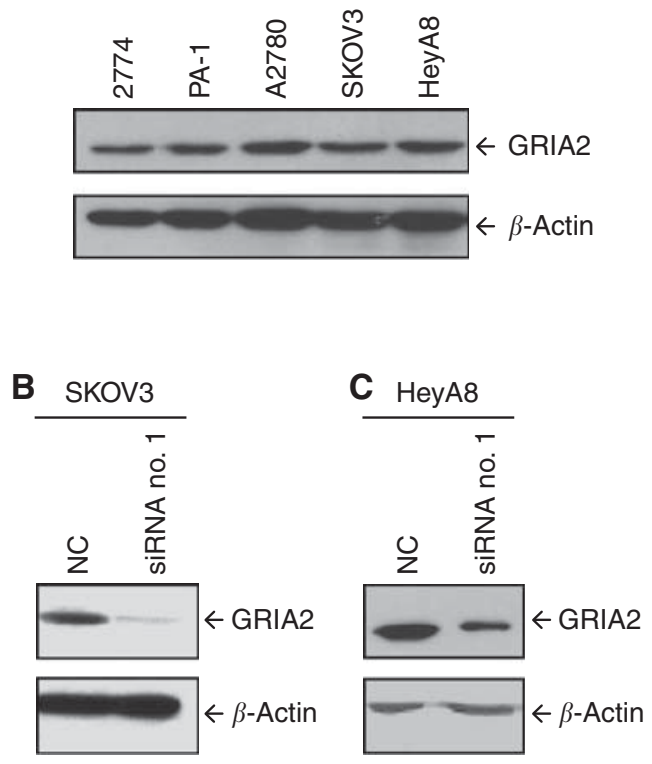

molecule with homology to L1CAM (close homologue of L1) and there are some reports in ovarian cancer. Senchenko et al, 2011 have reported that CHL1 could act as a putative tumour suppressor during the primary tumour growth. However, they also suggested that re-expression of the gene on the edge of tumour mass might promote local invasive growth and enable further metastatic spread in ovary, colon, and breast cancer. Wolterink et al (2010) also have reported that mAbs to the CHL1 prolonged survival and reduced tumour burden in nude mice. The role of CHL1 in ovarian cancer warrants further investigation.

In this study 57 genes were classified as differentially expressed between chemoresistant and chemosensitive tumours, which strengthens the theory that biological differences exist according to chemosensitivity. Further analysis of the genes differentially expressed among these tumours is of great interest to find candidate genes that may be used as prognostic markers in patients with ovarian cancer. The identification of GRIA2 among the most differentially expressed genes provides interesting information on the prognosis of patients with serous papillary ovarian adenocarcinoma.

\section{Conflict of interest}

The authors declare no conflict of interest.

\section{ACKNOWLEDGEMENTS}

This study was supported by a grant from the National R\&D Program for Cancer Control (0920010), and the Korea Healthcare technology R\&D Project (A092255), Ministry for Health, Welfare and Family affairs, Republic of Korea.

\section{Conflict of interest}

The authors declare no conflict of interest.
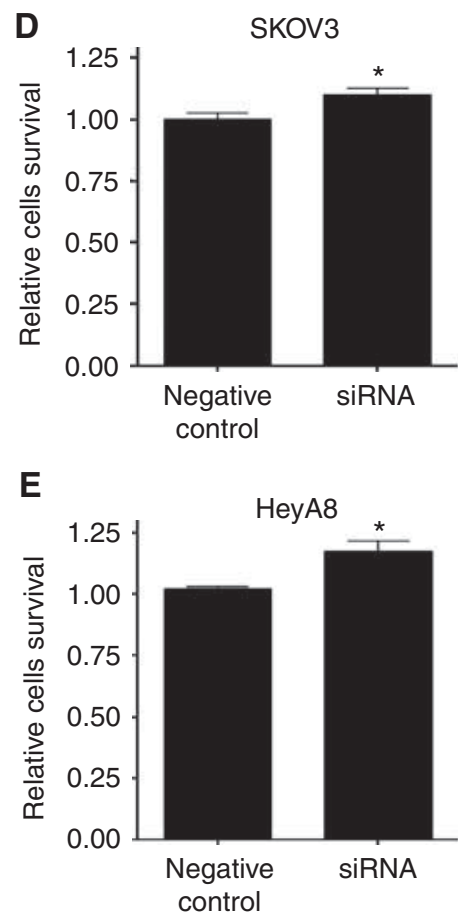

Figure 5 Effects of GRIA2 expression on the cell survival of epithelial ovarian cancer cells in vitro. (A) Expression of GRIA2 in epithelial ovarian cancer cell lines. Transfection of GIRA2 siRNA (I00 nM) for $72 \mathrm{~h}$ reduced GRIA2 protein expression of SKOV3 (B) and HeyA8 (C) cells compared with negative control. Transfection of GIRA2 siRNA (I00 nM) for $72 \mathrm{~h}$ increased cell survival of SKOV3 (D) and HeyA8 (E) cells compared with controls as assessed by MTT assay. Columns, mean of three independent experiments; bars, s.e. $(* P<0.05)$. 
Supplementary Information accompanies the paper on British

\section{REFERENCES}

Abdul M, Hoosein N (2005) N-methyl-D-aspartate receptor in human prostate cancer. J Membr Biol 205: 125-128

Bachvarov D, L'Esperance S, Popa I, Bachvarova M, Plante M, Tetu B (2006) Gene expression patterns of chemoresistant and chemosensitive serous epithelial ovarian tumors with possible predictive value in response to initial chemotherapy. Int J Oncol 29: 919-933

Behar TN, Scott CA, Greene CL, Wen X, Smith SV, Maric D, Liu QY, Colton CA, Barker JL (1999) Glutamate acting at NMDA receptors stimulates embryonic cortical neuronal migration. J Neurosci 19: 4449-4461

Berchuck A, Iversen ES, Lancaster JM, Pittman J, Luo J, Lee P, Murphy S, Dressman HK, Febbo PG, West M, Nevins JR, Marks JR (2005) Patterns of gene expression that characterize long-term survival in advanced stage serous ovarian cancers. Clin Cancer Res 11: 3686-3696

Beretta F, Bassani S, Binda E, Verpelli C, Bello L, Galli R, Passafaro M (2009) The GluR2 subunit inhibits proliferation by inactivating Src-MAPK signalling and induces apoptosis by means of caspase 3/6-dependent activation in glioma cells. Eur J Neurosci 30: 25-34

Cancer Genome Atlas Research Network (2011) Integrated genomic analyses of ovarian carcinoma. Nature 474: 609-615

Collins Y, Tan DF, Pejovic T, Mor G, Qian F, Rutherford T, Varma R McQuaid D, Driscoll D, Jiang M, Deeb G, Lele S, Nowak N, Odunsi K (2004) Identification of differentially expressed genes in clinically distinct groups of serous ovarian carcinomas using cDNA microarray. Int J Mol Med 14: 43-53

du Bois A, Luck HJ, Meier W, Adams HP, Mobus V, Costa S, Bauknecht T, Richter B, Warm M, Schroder W, Olbricht S, Nitz U, Jackisch C, Emons G, Wagner U, Kuhn W, Pfisterer J (2003) A randomized clinical trial of cisplatin/paclitaxel $v s$ carboplatin/paclitaxel as first-line treatment of ovarian cancer. J Natl Cancer Inst 95: 1320-1329

Dupuy A, Simon RM (2007) Critical review of published microarray studies for cancer outcome and guidelines on statistical analysis and reporting. J Natl Cancer Inst 99: 147-157

Greathouse KL, Cook JD, Lin K, Davis BJ, Berry TD, Bredfeldt TG, Walker CL (2008) Identification of uterine leiomyoma genes developmentally reprogrammed by neonatal exposure to diethylstilbestrol. Reprod Sci 15: 765-778

Hansen KB, Yuan H, Traynelis SF (2007) Structural aspects of AMPA receptor activation, desensitization and deactivation. Curr Opin Neurobiol 17: 281-288

Hartmann LC, Lu KH, Linette GP, Cliby WA, Kalli KR, Gershenson D, Bast RC, Stec J, Iartchouk N, Smith DI, Ross JS, Hoersch S, Shridhar V, Lillie J, Kaufmann SH, Clark EA, Damokosh AI (2005) Gene expression profiles predict early relapse in ovarian cancer after platinum-paclitaxel chemotherapy. Clin Cancer Res 11: 2149-2155

Herner A, Sauliunaite D, Michalski CW, Erkan M, De Oliveira T, Abiatari I, Kong B, Esposito I, Friess H, Kleeff J (2011) Glutamate increases pancreatic cancer cell invasion and migration via AMPA receptor activation and Kras-MAPK signaling. Int J Cancer 129: 2349-2359

Hollmann M, Heinemann S (1994) Cloned glutamate receptors. Annu Rev Neurosci 17: 31-108

Huang da W, Sherman BT, Lempicki RA (2009a) Bioinformatics enrichment tools: paths toward the comprehensive functional analysis of large gene lists. Nucleic Acids Res 37: 1-13

Huang da W, Sherman BT, Lempicki RA (2009b) Systematic and integrative analysis of large gene lists using DAVID bioinformatics resources. Nat Protoc 4: 44-57

Ikonomidou C, Bosch F, Miksa M, Bittigau P, Vockler J, Dikranian K, Tenkova TI, Stefovska V, Turski L, Olney JW (1999) Blockade of NMDA receptors and apoptotic neurodegeneration in the developing brain. Science 283: 70-74

International Collaborative Ovarian Neoplasm Group (2002) Paclitaxel plus carboplatin $v s$ standard chemotherapy with either singleagent carboplatin or cyclophosphamide, doxorubicin, and cisplatin in women with ovarian cancer: the ICON3 randomised trial. Lancet 360: 505-515

Irizarry RA, Hobbs B, Collin F, Beazer-Barclay YD, Antonellis KJ, Scherf U, Speed TP (2003) Exploration, normalization, and summaries of high density oligonucleotide array probe level data. Biostatistics 4: 249-264

Ishiuchi S, Yoshida Y, Sugawara K, Aihara M, Ohtani T, Watanabe T, Saito N, Tsuzuki K, Okado H, Miwa A, Nakazato Y, Ozawa S (2007) Ca2 +

Journal of Cancer website (http://www.nature.com/bjc)

permeable AMPA receptors regulate growth of human glioblastoma via Akt activation. J Neurosci 27: 7987-8001

Joo JY, Kim BW, Lee JS, Park JY, Kim S, Yun YJ, Lee SH, Rhim H, Son H (2007) Activation of NMDA receptors increases proliferation and differentiation of hippocampal neural progenitor cells. J Cell Sci 120: 1358-1370

Kim CJ, Lee JW, Choi JJ, Choi HY, Park YA, Jeon HK, Sung CO, Song SY, Lee YY, Choi CH, Kim TJ, Lee JH, Kim BG, Bae DS (2010) High claudin-7 expression is associated with a poor response to platinum-based chemotherapy in epithelial ovarian carcinoma. Eur J Cancer 47: 918-925

Koch CM, Wagner W (2011) Epigenetic-aging-signature to determine age in different tissues. Aging 3: 1018-1027

Konstantinopoulos PA, Spentzos D, Cannistra SA (2008) Gene-expression profiling in epithelial ovarian cancer. Nat Clin Pract Oncol 5: 577-587

Lancaster JM, Dressman HK, Whitaker RS, Havrilesky L, Gray J, Marks JR, Nevins JR, Berchuck A (2004) Gene expression patterns that characterize advanced stage serous ovarian cancers. J Soc Gynecol Investig 11: 51-59

Lee JW, Choi CH, Choi JJ, Park YA, Kim SJ, Hwang SY, Kim WY, Kim TJ Lee JH, Kim BG, Bae DS (2008) Altered MicroRNA expression in cervical carcinomas. Clin Cancer Res 14: 2535-2542

Leja J, Essaghir A, Essand M, Wester K, Oberg K, Totterman TH, Lloyd R, Vasmatzis G, Demoulin JB, Giandomenico V (2009) Novel markers for enterochromaffin cells and gastrointestinal neuroendocrine carcinomas. Mod Pathol 22: 261-272

Michalski CW, Oti FE, Erkan M, Sauliunaite D, Bergmann F, Pacher P, Batkai S, Muller MW, Giese NA, Friess H, Kleeff J (2008) Cannabinoids in pancreatic cancer: correlation with survival and pain. Int J Cancer 122: 742-750

Mok SC, Bonome T, Vathipadiekal V, Bell A, Johnson ME, Wong KK, Park DC, Hao K, Yip DK, Donninger H, Ozbun L, Samimi G, Brady J, Randonovich M, Pise-Masison CA, Barrett JC, Wong WH, Welch WR, Berkowitz RS, Birrer MJ (2009) A gene signature predictive for outcome in advanced ovarian cancer identifies a survival factor: microfibrilassociated glycoprotein 2. Cancer Cell 16: 521-532

Ouellet V, Guyot MC, Le Page C, Filali-Mouhim A, Lussier C, Tonin PN, Provencher DM, Mes-Masson AM (2006) Tissue array analysis of expression microarray candidates identifies markers associated with tumor grade and outcome in serous epithelial ovarian cancer Int J Cancer 119: 599-607

Rao VR, Finkbeiner S (2007) NMDA and AMPA receptors: old channels new tricks. Trends Neurosci 30: 284-291

Runnebaum IB, Stickeler E (2001) Epidemiological and molecular aspects of ovarian cancer risk. J Cancer Res Clin Oncol 127: 73-79

Rzeski W, Turski L, Ikonomidou C (2001) Glutamate antagonists limit tumor growth. Proc Natl Acad Sci USA 98: 6372-6377

Saeed AI, Bhagabati NK, Braisted JC, Liang W, Sharov V, Howe EA, Li J, Thiagarajan M, White JA, Quackenbush J (2006) TM4 microarray software suite. Methods Enzymol 411: 134-193

Saeed AI, Sharov V, White J, Li J, Liang W, Bhagabati N, Braisted J, Klapa M, Currier T, Thiagarajan M, Sturn A, Snuffin M, Rezantsev A, Popov D, Ryltsov A, Kostukovich E, Borisovsky I, Liu Z, Vinsavich A, Trush V, Quackenbush J (2003) TM4: a free, open-source system for microarray data management and analysis. Biotechniques 34: 374-378

Seeburg PH (1993) The TiPS/TINS lecture: the molecular biology of mammalian glutamate receptor channels. Trends Pharmacol Sci 14: 297-303

Senchenko VN, Krasnov GS, Dmitriev AA, Kudryavtseva AV, Anedchenko EA, Braga EA, Pronina IV, Kondratieva TT, Ivanov SV, Zabarovsky ER, Lerman MI (2011) Differential expression of CHL1 gene during development of major human cancers. PLoS One 6: e15612

Spentzos D, Levine DA, Ramoni MF, Joseph M, Gu X, Boyd J, Libermann TA, Cannistra SA (2004) Gene expression signature with independent prognostic significance in epithelial ovarian cancer. J Clin Oncol 22: 4700-4710

Takeda M, Haga M, Yamada H, Kinoshita M, Otsuka M, Tsuboi S, Moriyama Y (2000) Ionotropic glutamate receptors expressed in human retinoblastoma Y79 cells. Neurosci Lett 294: 97-100

Trinh XB, Tjalma WA, Dirix LY, Vermeulen PB, Peeters DJ, Bachvarov D, Plante M, Berns EM, Helleman J, Van Laere SJ, van Dam PA (2011) Microarray-based oncogenic pathway profiling in advanced serous papillary ovarian carcinoma. PLoS One 6: e22469 
Tsibris JC, Maas S, Segars JH, Nicosia SV, Enkemann SA, O'Brien WF, Spellacy WN (2003) New potential regulators of uterine leiomyomata from DNA arrays: the ionotropic glutamate receptor GluR2. Biochem Biophys Res Commun 312: 249-254

Wolterink S, Moldenhauer G, Fogel M, Kiefel H, Pfeifer M, Luttgau S, Gouveia R, Costa J, Endell J, Moebius U, Altevogt P (2010) Therapeutic antibodies to human L1CAM: functional characterization and application in a mouse model for ovarian carcinoma. Cancer Res 70: 2504-2515 Yoshioka A, Ikegaki N, Williams M, Pleasure D (1996) Expression of $\mathrm{N}$-methyl-D-aspartate (NMDA) and non-NMDA glutamate receptor genes in neuroblastoma, medulloblastoma, and other cells lines. J Neurosci Res 46: 164-178

This work is published under the standard license to publish agreement. After 12 months the work will become freely available and the license terms will switch to a Creative Commons Attribution-NonCommercial-Share Alike 3.0 Unported License. 